Article

\title{
Mild and Highly Efficient Copper(I) Inspired Acylation of Alcohols and Polyols
}

\author{
Enoch A. Mensah * and Lindsey Earl \\ School of Natural Sciences, Indiana University Southeast, New Albany, IN 47150, USA; learl@umail.iu.edu \\ * Correspondence: mensahe@ius.edu; Tel.: +1-812-941-2305 \\ Academic Editor: Kei Manabe \\ Received: 23 December 2016; Accepted: 12 January 2017; Published: 18 January 2017
}

\begin{abstract}
A new and highly efficient method mediated by tetrakis(acetonitrile)copper(I) triflate for activating both simple and highly hindered anhydrides in the acylation of alcohols and polyols is described. This new acylation method is mild and mostly proceeds at room temperature with low catalyst loading. The method is versatile and has been extended to a wide variety of different alcohol substrates to afford the corresponding ester products in good to excellent yields.
\end{abstract}

Keywords: acylation; acetic anhydride; isobutyric anhydride; pivalic anhydride; polyols; copper(I) species

\section{Introduction}

The masking of hydroxyl groups to prevent side reactions during long synthetic reaction sequences continues to be of paramount importance in organic synthesis. These protection protocols usually involves the transformation of the hydroxyl groups to their corresponding ester analogs.

While the use of acetic anhydride, pyridine, and DMAP remains popular in transforming hydroxyl groups to the corresponding acetate esters [1], the noxious smell of pyridine as well as its high boiling point, makes its removal relatively difficult and can potentially complicate product isolation in synthetic protocols run on a small scale.

In an attempt to avoid the use of pyridine during the masking of hydroxyl groups, several alternative methods have been reported in recent years. Some notable methods include the use of $\mathrm{I}_{2}$ [2-4], $\mathrm{Br}_{2}$ [5] montmorillonite $\mathrm{K}-10$ [6], $\mathrm{FeCl}_{3}$ [7], $\mathrm{TiCl}_{4}-\mathrm{AgClO}_{4}$ [8], $\mathrm{LiClO}_{4}$ [9], $\mathrm{CuSO}_{4} \cdot 5 \mathrm{H}_{2} \mathrm{O}$ [10], TMSOTf [11], $\mathrm{Bu}_{3} \mathrm{P}$ in $\mathrm{CH}_{2} \mathrm{Cl}_{2}$ [12,13], $\mathrm{La}\left(\mathrm{NO}_{3}\right)_{3} \cdot 6 \mathrm{H}_{2} \mathrm{O}$ [14], $\mathrm{HClO}_{4}-\mathrm{SiO}_{2}$ [15], molecular sieves [16], $\mathrm{NaHCO}_{3}$ [17], $\mathrm{Mg}\left(\mathrm{NTf}_{2}\right)_{2}$ [18], 3-nitrobenzeneboronic acid [19], alumina [20], NBS [21], TaCl 5 [22], $\mathrm{VO}(\mathrm{OAc})_{2}$ [23] and metal triflates such as $\mathrm{Pd}(\mathrm{PhCN})_{2}(\mathrm{OTf})$ [24], $\mathrm{Cu}(\mathrm{OTf})_{2}$ [25], $\mathrm{Bi}(\mathrm{OTf})_{2}$ [26], $\mathrm{In}(\mathrm{OTf})_{2}[27,28], \mathrm{Sc}(\mathrm{OTf})_{2}$ [29], Ce(OTf $)_{2}$ [30], and $\mathrm{CoCl}_{2}$ [31,32].

While all these methods provide a viable alternative in the acetylation of alcohols, long reaction times, high temperature requirements, and high catalyst loading required in some of these protocols has necessitated the need for the development of a new method of protecting hydroxyl groups to complement the existing methods.

In recent years, the use of copper(I) species as efficient catalysts in various cross-coupling reactions in the formation of $\mathrm{C}-\mathrm{C}, \mathrm{C}-\mathrm{N}$, and $\mathrm{C}-\mathrm{O}$ linkages during organic transformations, and in the synthesis of natural products, has received considerable attention. Sharpless et al. as well as the Meldal research group independently employed the use of copper(I) catalysis in the formation of a cyclic adduct during azide-alkyne cycloaddition reactions $[33,34]$. In the synthesis of $(-)$-galbulimima alkaloid, the Movassaghi research group reported the use of copper-inspired coupling of vinyl bromide and oxazolidinone as one of its key intermediate steps [35]. A similar strategy was also employed in the synthesis of himandrine alkaloid [36]. Bergman et al. also reported the use of copper catalyzed 
amidation reactions as one of its key strategies in the synthesis of the alkaloid vasicoline [37]. Again, Buchwald et al. also reported a domino $\mathrm{Cu}(\mathrm{I})$ catalyzed amidation/nucleophilic substitution protocol to access substituted indolines, a very important and common structural motif in many bioactive natural products [38].

In spite of the extensive use of copper-mediated catalysis in natural product synthesis, the use of copper(I) species in activating both simple and hindered anhydrides towards the masking of various hydroxyl groups in organic synthesis have not been investigated. We herein report a new, mild, and simple protocol that utilizes tetrakis(acetonitrile)copper(I) triflate as a highly efficient catalyst in the acylation of simple alcohols and polyols.

\section{Results and Discussion}

After an extensive preliminary study using a simple alcohol such as phenol $\mathbf{1}$ (1 equivalent) as the model substrate and acetic anhydride (4 equivalents) as the acetylation agent, we found that $1 \mathrm{~mol} \%$ of tetrakis(acetonitrile)copper(I) triflate was able to efficiently catalyze the transformation of phenol 1 to the corresponding phenyl acetate $\mathbf{2}$ in $3 \mathrm{~min}$ and in quantitative yield.

This remarkable and rapid transformation of phenol 1 to its corresponding phenyl acetate $\mathbf{2}$ at low catalyst loading was very significant and may suggest the high capacity of copper(I) species to activate simple anhydrides towards the masking of hydroxyl groups. As a result of the excellent initial results with phenol, the versatility and efficacy of tetrakis(acetonitrile)copper(I) triflate was also explored using a variety of different alcohols as substrates and with acetic anhydride as the acetylating agent (Table 1).

Table 1. Acetylation of alcohols with acetic anhydride catalyzed by $\mathrm{Cu}\left(\mathrm{CH}_{3} \mathrm{CN}\right)_{4} \mathrm{OTf}$.

Entry
$(1$ equiv. $)$


Table 1. Cont.

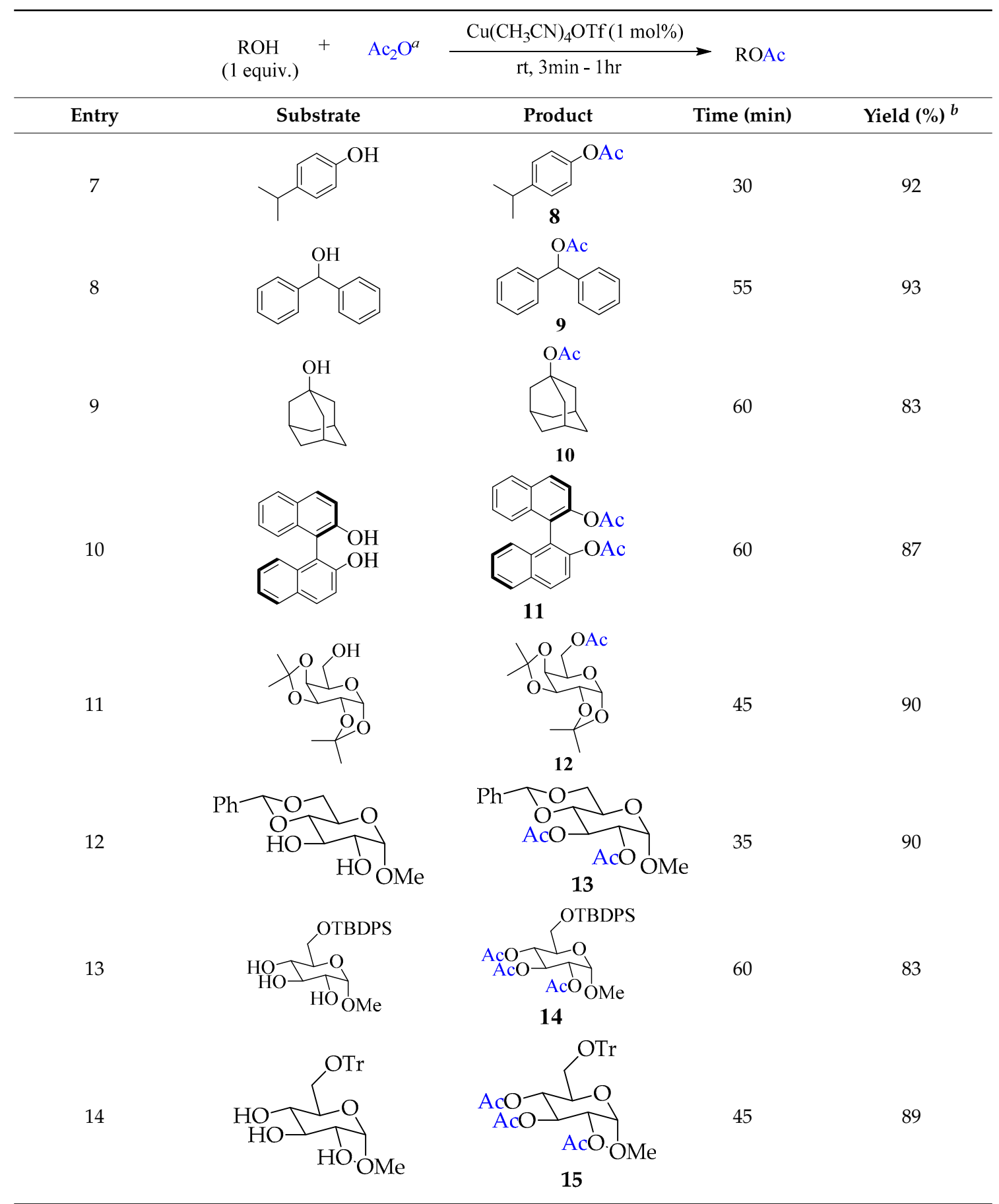

\footnotetext{
${ }^{a}$ Reactions were carried out using 4 equiv. of acetic anhydride per hydroxyl group; ${ }^{b}$ Isolated yield.
}

In all instances, there were smooth conversion to their corresponding esters 3-8 in excellent yields and in short reaction times (Table 1, Entries 2-7).

With these encouraging results, the efficacy of the $\mathrm{Cu}(\mathrm{I})$ catalyst in the presence of highly hindered alcohol substrates was also explored. In this study, the acetylation reaction was performed using highly hindered alcohol substrates such as diphenyl methanol and adamantanol (Table 1, Entries 8-9). Remarkably, there was a facile transformation of these hindered alcohols to their corresponding esters $\mathbf{9}$ and 10 respectively in excellent yields. 
Since several acid labile hydroxyl-protecting groups are routinely employed in organic synthesis during long synthetic reaction sequences, the efficacy of this new acetylation protocol was also investigated in the presence of other acid labile hydroxyl-protecting groups. Using the acetonide protected galactose as a substrate, remarkably, the acid labile acetonide group survived this new reaction protocol, affording the corresponding protected galactose ester $\mathbf{1 2}$ in excellent yield (Table 1, Entry 11).

In the synthesis of oligosaccharides, functionalization of the monosaccharide units prior to their assembly is usually crucial. One of the main synthetic strategies used to achieve this objective is to employ the use of acid labile benzylidine acetal as a protecting group. This acid labile benzylidine acetal is routinely used to mask diols in a 1,2 and 1,3 configuration [39,40]. The tolerance of the acid sensitive benzylidene acetal to this acetylation protocol was also investigated using a benzylidene acetal protected glucose diol as the substrate. Gratifyingly, the acid labile benzylidene acetal-protecting group survived, affording the fully protected sugar 13 in excellent yield (Table 1, Entry 12).

To further explore the scope and generality of this acetylation protocol, the efficacy of the $\mathrm{Cu}(\mathrm{I})$ catalyst was also explored in the presence of a silyl- and trityl-protecting groups. Silyl- and trityl-protecting groups are among the most common hydroxyl-protecting groups used in organic synthesis. When silyl and trityl protected sugars were used as substrates, again, both protecting groups survived, affording fully acetylated sugars $\mathbf{1 4}$ and $\mathbf{1 5}$ respectively in excellent yields. (Table 1, Entries 13 and 14). All these results may suggest that this new $\mathrm{Cu}(\mathrm{I})$-inspired acetylation protocol is not only highly efficient but also mild as well.

In the formation of glycosidic linkages during the synthesis of polysaccharides, one of the initial steps usually involve the acetylation of the polyhydroxyl monosaccharides. To probe the limits of this new acetylation method, the versatility and efficacy of this protocol was again investigated by using polyols derived from both carbohydrates and non-carbohydrates as substrates (Scheme 1).
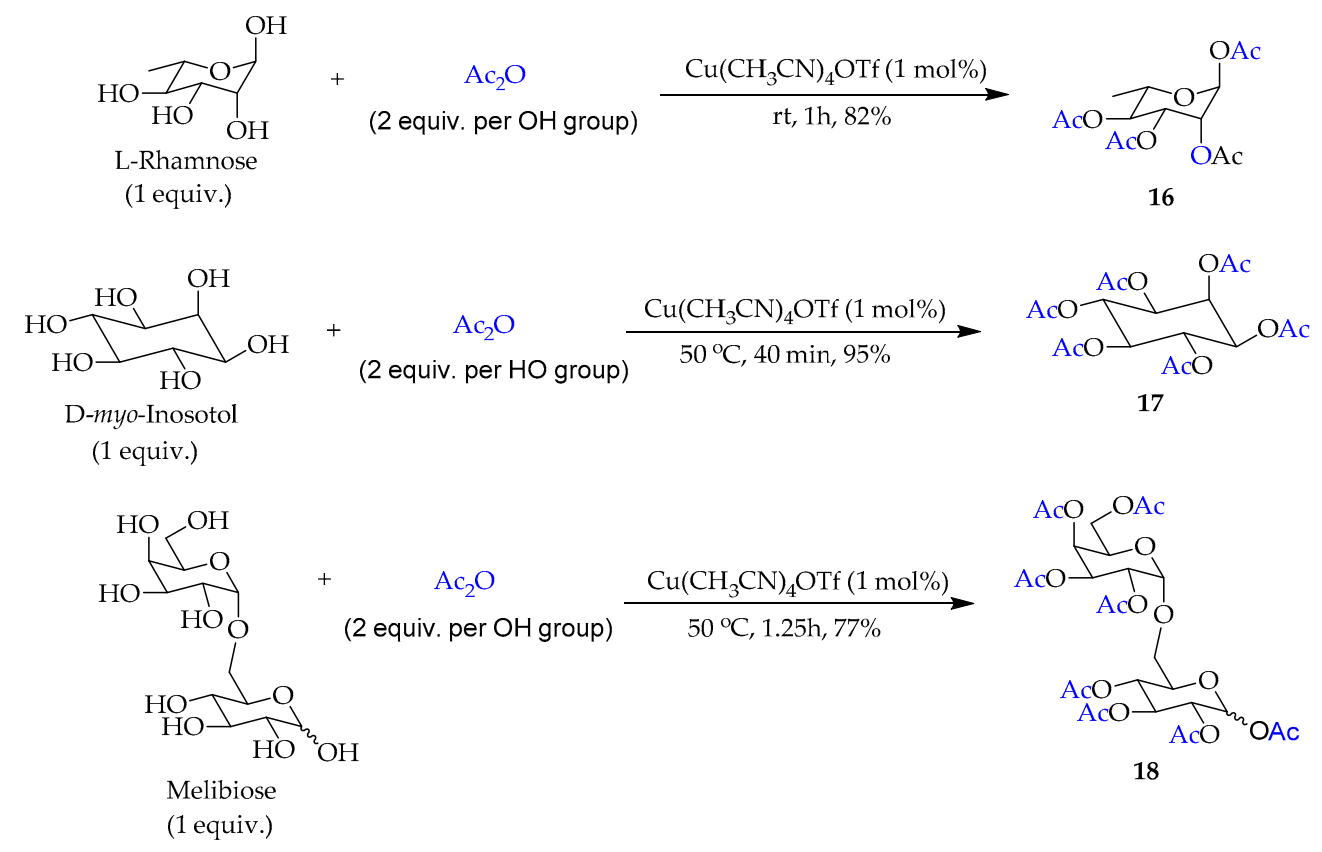

Scheme 1. $\mathrm{Cu}\left(\mathrm{CH}_{3} \mathrm{CN}\right)_{4} \mathrm{OTf}$ catalyzed acetylation of polyols.

Using L-rhamnose sugar as substrate, the acetylation reaction proceeded with ease and at room temperature affording the fully acetylated sugar 16 in good yield (Scheme 1). With polyhydroxyl myo-inositol as substrate, the acetylation reaction was quite sluggish; however, upon warming up the reaction, the acetylation reaction proceeded smoothly to obtain the fully acetylated D-myo-inositol 17 in excellent yield (Scheme 1). 
To continue exploring the scope and limits of this protocol, the $\mathrm{Cu}(\mathrm{I})$-catalyzed acetylation reaction was again performed using a disaccharide-derived polyol such as melibiose as substrate. Although the reaction was also initially sluggish, upon warming the reaction to $50^{\circ} \mathrm{C}$, remarkably, there was a facile transformation of the polyol to the fully acetylated disaccharide $\mathbf{1 8}$ in good yield (Scheme 1).

As a result of the excellent versatility and efficacy of this catalyst, we again investigated the capacity of this catalyst in activating a relatively hindered acylating agent such as isobutyric anhydride in the acylation of alcohols (Table 2).

Table 2. Acylation of alcohols with isobutyric anhydride catalyzed by $\mathrm{Cu}\left(\mathrm{CH}_{3} \mathrm{CN}\right)_{4} \mathrm{OTf}$.

\begin{tabular}{|c|c|c|c|c|}
\hline Entry & Substrate & Product & Time (min) & Yield (\%) ${ }^{b}$ \\
\hline 1 & & 19 & 15 & 92 \\
\hline 2 & & 20 & 180 & 93 \\
\hline 3 & & 21 & 30 & 90 \\
\hline 4 & & 22 & 60 & 93 \\
\hline 5 & & 23 & 90 & 89 \\
\hline 6 & & 24 & 60 & 91 \\
\hline 7 & & 25 & 210 & 88 \\
\hline 8 & & 26 & 90 & 85 \\
\hline 9 & & 27 & 120 & 90 \\
\hline
\end{tabular}

\footnotetext{
${ }^{a}$ Reaction was carried out using 4 equiv. of isobutyric anhydride per hydroxyl group. ${ }^{b}$ Isolated yield.
} 
With phenol as the starting substrate and isobutyric anhydride as the acylation agent, the acylation reaction again proceeded smoothly with only $1 \mathrm{~mol} \%$ catalyst loading, affording the phenyl isobutyrate 19 in excellent yield (Table 2, Entry 1). This exciting results prompted us to again investigate the scope of the catalyst using different alcohols with different steric encumbrance as substrate. In all cases, the acylation reaction afforded the corresponding acylated products $\mathbf{2 0 - 2 6}$ in excellent yields (Table 2, Entries 2-8). Remarkably, the acylation reaction again proceeded smoothly even with a hindered substrate such as diphenyl methanol at $1 \mathrm{~mol} \%$ catalyst loading, affording the corresponding ester 27 in excellent yield (Table 2, Entry 9).

To further study the generality, scope, and efficiency of this new method of acylating alcohols, the capacity of $\mathrm{Cu}(\mathrm{I})$ catalysts to activate a highly hindered acylating agent such as pivalic anhydride was also investigated using different and sterically diverse alcohols as substrates (Table 3).

Table 3. Pivalation of alcohols catalyzed by $\mathrm{Cu}\left(\mathrm{CH}_{3} \mathrm{CN}\right)_{4} \mathrm{OTf}$.

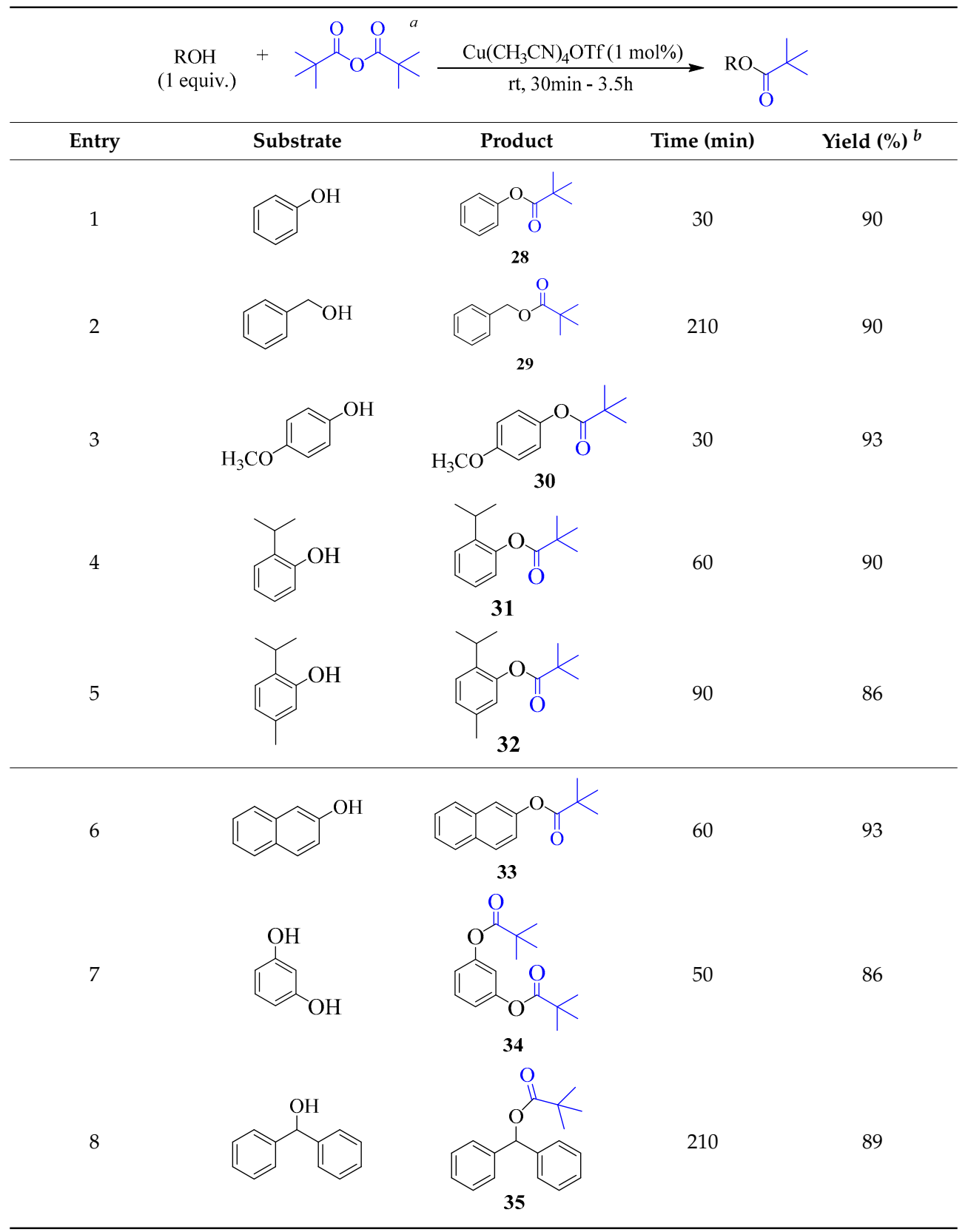

${ }^{a}$ Reaction was carried out using 4 equiv. of pivalic anhydride per hydroxyl group; ${ }^{b}$ Isolated yield. 
It was gratifying to note that, in all cases using different alcohol substrates, the pivalation reaction proceeded with ease even with hindered substrates, transforming the alcohol substrates to the corresponding pivalate esters 28-35 in good to excellent yield.

These results are noteworthy because it demonstrates the capacity of $\mathrm{Cu}(\mathrm{I})$ catalyst tetrakis(acetonitrile)copper(I) triflate to activate both simple and highly hindered acid anhydrides towards the masking of hydroxyl groups.

While this protocol resulted in the facile transformation of the alcohols to the corresponding esters using different acylating agents, separating the fully acylated products from the excess isobutyric anhydride or pivalic anhydride used became problematic. To circumvent this problem, the methanolysis protocol reported by Otera et al. [26] was adopted and modified to decompose the excess isobutyric anhydride and pivalic anhydride.

To explore the origin of the observed catalysis, a control experiment with phenol as the substrate and acetic anhydride as the acylating agent was carried out in the absence of the $\mathrm{Cu}(\mathrm{I})$ catalyst. In this control reaction, there were no appreciable conversion of the phenol to the corresponding ester $\mathbf{2}$ even after stirring the reaction for $5 \mathrm{~h}$. Similar results were also obtained when isobutyric anhydride and pivalic anhydrides were used as the acylating agents.

The lack of observable product formation obtained with phenol and acetic anhydride in the absence of the $\mathrm{Cu}(\mathrm{I})$ catalyst was in sharp contrast to the rapid acetylation of phenol in the presence of the catalyst (Table 1, Entry 1). Similarly, the results obtained during acylation of phenol when isobutyric anhydride and pivalic anhydride were used as the acylating agents in the presence of the $\mathrm{Cu}(\mathrm{I})$ catalyst (Table 2, Entry 1 and Table 3, Entry 1) were also in sharp contrast to the lack of product formation observed when the acylation reactions were carried out in the absence of the catalyst, which may suggest the crucial role of tetrakis(acetonitrile)copper(I) triflate in activating both simple and hindered anhydrides, thereby effecting the facile transformation of alcohols and polyols to their corresponding esters.

To further explore the source of the observed catalysis and the influence of the triflate counter ion, another control experiment was run with phenol as the substrate and acetic anhydride as the acylating agent. With $1 \mathrm{~mol} \%$ triflic acid as the catalyst, the reaction was completed within $5 \mathrm{~min}$ to afford the phenyl acetate in a $90 \%$ yield. When the control experiment was repeated using a $1 \mathrm{~mol} \%$ non-triflate $\mathrm{Cu}(\mathrm{I})$ source $-\mathrm{Cu}\left(\mathrm{CH}_{3} \mathrm{CN}\right)_{4} \mathrm{BF}_{4}$ - surprisingly, the acetylation reaction was very sluggish, proceeding to completion in $6 \mathrm{~h}$ and affording the phenyl acetate in a 92\% yield.

These results may suggest the crucial role of the triflate counter ion in the observed catalyzed acylation reactions and may also suggest the likelihood of an ancillary side reaction due to Bronsted catalysis.

\section{Experimental Section}

\subsection{Materials and Methods}

All other chemicals were obtained from commercial vendors and used without further purification.

All acylation reactions were performed in a dried and argon flushed round bottom flask. The reaction's progress was routinely monitored by analytical thin-layer chromatography (TLC) using a pre-coated silica gel glass plates. The products were identified and analyzed using IR, ${ }^{1} \mathrm{H}$ NMR, and ${ }^{13} \mathrm{C}$ NMR. The ${ }^{1} \mathrm{H}$ NMR spectra were recorded on a Varian $600 \mathrm{MHz}$ spectrometer (Agilent Technologies, Santa Clara, CA, USA.).

The ${ }^{13} \mathrm{C}$ NMR spectra were recorded on a Varian $150 \mathrm{MHz}$ spectrometer (Agilent Technologies, Santa Clara, CA, USA.) using $\mathrm{CDCl}_{3}$ as reference solvent.

\subsection{Typical Experimental Procedure for O-Acetylation of Alcohols with Acetic Anhydride}

An oven-dried and argon flushed $10 \mathrm{~mL}$ round-bottom flask was charged with Phenol (47.1 mg, $0.50 \mathrm{mmol}, 1.0$ equiv.) and acetic anhydride $(0.19 \mathrm{~mL}, 2.0 \mathrm{mmol}, 4.0$ equiv.). To this mixture, 
tetrakis(acetonitrile)copper(I) triflate $(1.9 \mathrm{mg}, 0.005 \mathrm{mmol}, 1 \mathrm{~mol} \%)$ was added. The reaction mixture was stirred at room temperature and monitored by TLC. When the reaction was complete, the excess acetic anhydride was decomposed with saturated aqueous $\mathrm{NaHCO}_{3}(2 \mathrm{~mL})$ and stirred for $45 \mathrm{~min}$. The resulting reaction mixture was directly introduced onto a short $\mathrm{SiO}_{2}$ column and purified by flash column chromatography $(6 / 1$, hexanes/ethyl acetate) to afford the phenyl acetate as pale yellow oil.

\subsection{Typical Experimental Procedure for O-Acylation of Alcohols with Isobutyric Anhydride}

An oven-dried and argon flushed $10 \mathrm{~mL}$ round-bottom flask was charged with phenol $(47.1 \mathrm{mg}$, $0.50 \mathrm{mmol}, 1.0$ equiv.) and isobutyric anhydride $(0.3 \mathrm{~mL}, 2.0 \mathrm{mmol}, 4.0$ equiv.). To this mixture, tetrakis(acetonitrile)copper(I) triflate $(1.9 \mathrm{mg}, 0.005 \mathrm{mmol}, 1 \mathrm{~mol} \%)$ was added. The reaction mixture was stirred at room temperature and monitored by TLC. When the reaction was complete, methanol $(3 \mathrm{~mL})$ was added and heated at $50{ }^{\circ} \mathrm{C}$ for $3 \mathrm{~h}$. The resulting reaction mixture was concentrated in vacuo and purified by flash column chromatography $(7 / 1$, hexanes/ethyl acetate) to afford the phenyl isobutyrate as a pale yellow oil.

\section{Conclusions}

In summary, a new, simple, and highly efficient method of masking hydroxyl group to the corresponding esters mediated by tetrakis(acetonitrile)copper(I) triflate has been developed. This acylation protocol is mild and versatile, and mostly proceeds at room temperature.

Supplementary Materials: The following are available online at www.mdpi.com/2073-4344/7/1/33/s1, Spectra data and Table S1: Preliminary studies of $\mathrm{Cu}\left(\mathrm{CH}_{3} \mathrm{CN}\right)_{4} \mathrm{OTf}$ catalyzed acetylation of phenol.

Acknowledgments: We gratefully acknowledge Indiana University Southeast for financial support. This research is also supported by Indiana University Southeast Research Support Program as well as the Indiana University Southeast Large Grant Program.

Author Contributions: Enoch Mensah conceived and designed the experiments. The experimental procedures were performed by Lindsey Earl and Enoch Mensah.

Conflicts of Interest: The authors declare no conflict of interest.

\section{References}

1. Hofle, G.; Steglich, W.; Vorbruggen, H. 4-Dialkylaminopyridines as Highly Active Acylation Catalysts. Angew. Chem. Int. Ed. 1978, 17, 569-583. [CrossRef]

2. Phukan, P. Iodine as an Extremely Powerful Catalyst for the Acetylation of Alcohols under solvent-free conditions. Tetrahedron Lett. 2004, 45, 4785-4787. [CrossRef]

3. Borah, R.; Deka, N.; Sarma, J.C. Iodine as an Acetyl Transfer Catalyst. J. Chem. Res. 1997, 110-111. [CrossRef]

4. Kartha, K.P.R.; Field, R.A. Iodine: A Versatile Reagent in Carbohydrate Chemistry IV. Per-O-acetylation, regioselective acylation and acetolysis. Tetrahedron 1997, 53, 11753-11766. [CrossRef]

5. Khan, A.T.; Choudhury, L.H.; Ghosh, S. Acetonyltriphenylphosphonium Bromide (ATPB): A Versatile Reagent for the Acylation of Alcohols, Phenols, Thiols and Amines and for 1,1-Diacylation of Aldehydes under Solvent-Free Conditions. Eur. J. Org. Chem. 2005, 2005, 2782-2787. [CrossRef]

6. Bhaskar, P.M.; Loganathan, D. Per-O-acetylation of sugars catalysed by montmorillonite K-10. Tetrahedron Lett. 1998, 39, 2215-2218. [CrossRef]

7. Dasgupta, F.; Singh, P.P.; Srivastava, H.C. Acetylation of carbohydrates using ferric chloride in acetic anhydride. Carbohydr. Res. 1980, 80, 346-349. [CrossRef]

8. Miyashita, M.; Shiina, I.; Miyoshi, S.; Mukaiyama, T. A New and Efficient Esterification Reaction via Mixed Anhydrides by the Promotion of a Catalytic Amount of Lewis Acid. Bull. Chem. Soc. Jpn. 1993, 66, 1516-1527. [CrossRef]

9. Lu, K.C.; Hsieh, S.Y.; Patkar, L.N.; Chen, C.T.; Lin, C.C. Simple and efficient per-O-acetylation of carbohydrates by lithium perchlorate catalyst. Tetrahedron 2004, 60, 8967-8973. [CrossRef] 
10. Heravi, M.M.; Behbahani, F.K.; Zadsirjan, V.; Oskooie, H.A. Copper(II) Sulfate Pentahydrate $\left(\mathrm{CuSO}_{4} \cdot 5 \mathrm{H}_{2} \mathrm{O}\right)$. A Green Catalyst for Solventless Acetylation of Alcohols and Phenols with Acetic Anhydride. J. Braz. Chem. Soc. 2006, 17, 1045-1047.

11. Procopiou, P.A.; Baugh, S.P.D.; Flack, S.S.; Inglis, G.G.A. An Extremely Powerful Acylation Reaction of Alcohols with Acid Anhydrides Catalyzed by Trimethylsilyl Trifluoromethanesulfonate. J. Org. Chem. 1998, 63, 2342-2347. [CrossRef]

12. Vedejs, E.; Diver, S.T. Tributylphosphine: A Remarkable Acylation Catalyst. J. Am. Chem. Soc. 1993, 115, 3358-3359. [CrossRef]

13. Vedejs, E.; Bennett, N.S.; Conn, L.M.; Diver, S.T.; Gingras, M.; Lin, S.; Oliver, P.A.; Peterson, M.J. Tributylphosphine-catalyzed acylations of alcohols: Scope and related reactions. J. Org. Chem. 1993, 58, 7286-7288. [CrossRef]

14. Reddy, T.S.; Narasimhulu, M.; Suryakiran, N.; Mahesh, K.C.; Ashalatha, K.; Venkateswarlu, Y. A Mild and

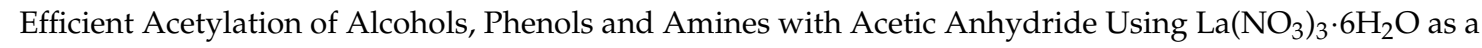
Catalyst Under Solvent-free Conditions. Tetrahedron Lett. 2006, 47, 6825-6829. [CrossRef]

15. Misra, A.K.; Tiwari, P.; Madhusudan, S.K. $\mathrm{HClO}_{4}-\mathrm{SiO}_{2}$ Catalyzed per-O-Acetylation of Carbohydrates. Carbohydr. Res. 2005, 340, 325-329. [CrossRef] [PubMed]

16. Adinolfi, M.; Barone, G.; Iadonisi, A.; Schiattarella, M. An Easy Approach for the Acetylation of Saccharidic Alcohols. Applicability for Regioselective Protections. Tetrahedron Lett. 2003, 44, 4661-4663. [CrossRef]

17. Lugemwa, F.N.; Shaikh, K.; Hochstedt, E. Facile and efficient acetylation of primary alcohols and phenols with acetic anhydride aatalyzed by dried sodium bicarbonate. Catalysts 2013, 3, 954-965. [CrossRef]

18. Chakraborti, A.K.; Shivani. Magnesium Bistrifluoromethanesulfonimide as a New and Efficient Acylation Catalyst. J. Org. Chem. 2006, 71, 5785-5788. [CrossRef] [PubMed]

19. Tale, R.H.; Adude, R.N. A novel 3-nitrobenzeneboronic acid as an extremely mild and environmentally benign catalyst for the acetylation of alcohols under solvent-free conditions. Tetrahedron Lett. 2006, 47, 7263-7265. [CrossRef]

20. Breton, G.W.; Kurtz, M.J.; Kurtz, S.L. Acetylation of unsymmetrical diols in the presence of $\mathrm{Al}_{2} \mathrm{O}_{3}$. Tetrahedron Lett. 1997, 38, 3825-3828. [CrossRef]

21. Karimi, B.; Seradj, H. N-Bromosuccinimide (NBS), a novel and highly effective catalyst for acetylation of alcohols under mild reaction conditions. Synlett 2001, 2001, 519-520. [CrossRef]

22. Chandrasekhar, S.; Ramachander, T.; Takhi, M. Acylation of alcohols with acetic anhydride catalyzed by $\mathrm{TaCl}_{5}$ : Some implications in kinetic resolution. Tetrahedron Lett. 1998, 39, 3263-3266. [CrossRef]

23. Choudary, B.M.; Kantam, M.L.; Neeraja, V.; Bandyopadhyay, T.; Reddy, P.N. Vanadyl(IV) acetate, a new reusable catalyst for acetylation of alcohols. J. Mol. Catal. A 1999, 140, 25-29. [CrossRef]

24. Mensah, E.A.; Franscisco, R.R.; Standiford, E.S. Highly Efficient Cationic Palladium Catalyzed Acetylation of Alcohols and Carbohydrate-Derived Polyols. Catalysts 2016, 6, 27. [CrossRef]

25. Chandra, K.L.; Saravanan, P.; Singh, R.K.; Singh, V.K. Lewis Acid Catalyzed Acylation Reactions: Scope and Limitations. Tetrahedron 2002, 58, 1369-1374. [CrossRef]

26. Orita, A.; Tanahashi, C.; Kakuda, A.; Otera, J. Highly Powerful and Practical Acylation of Alcohols with Acid Anhydride Catalyzed by Bi(OTf $)_{3}$. J. Org. Chem. 2001, 66, 8926-8934. [CrossRef] [PubMed]

27. Bizier, N.P.; Atkins, S.R.; Helland, L.C.; Colvin, S.F.; Twitchell, J.R.; Cloninger, M.J. Indium Triflate Catalyzed Peracetylation of Carbohydrates. Carbohydr. Res. 2008, 343, 1814-1818. [CrossRef] [PubMed]

28. Chauhan, K.K.; Frost, C.G.; Love, I.; Waite, D. Indium Triflate: An Efficient Catalyst for Acylation reactions. Synlett 1999, 1999, 1743-1744. [CrossRef]

29. Ishihara, K.; Kubota, M.; Kurihara, H.; Yamamoto, H. Scandium Trifluoromethanesulfonate as an extremely active lewis acid catalyst in acylation of alcohols with acid anhydrides and mixed anhydrides. J. Org. Chem. 1996, 61, 4560-4567. [CrossRef] [PubMed]

30. Dalpozzo, R.; De Nino, A.; Maiuolo, L.; Procopio, A.; Nardi, M.; Bartoli, M.; Romeo, R. Highly efficient and versatile acetylation of alcohols catalyzed by cerium(III) triflate. Tetrahedron Lett. 2003, 44, 5621-5624. [CrossRef]

31. Velusamy, S.; Borpuzari, S.; Punniyamurthy, T. Cobalt(II)-Catalyzed Direct Acetylation of Alcohols with Acetic acid. Tetrahedron 2005, 61, 2011-2015. [CrossRef]

32. Mulla, S.A.R.; Inamdar, S.M.; Pathan, M.Y.; Chavan, S.S. Highly Efficient Cobalt (II) Catalyzed O-Acylation of Alcohols and Phenols under Solvent-Free Conditions. Open J. Synth. Theory Appl. 2012, 1, 31-35. [CrossRef] 
33. Rostovtsev, V.V.; Green, L.G.; Fokin, V.V.; Sharpless, K.B. A Stepwise Huisgen Cycloaddition Process: Copper(I)-Catalyzed Regioselective "Ligation" of Azides and Terminal Alkynes. Angew. Chem. Int. Ed. 2002, 41, 2596-2599. [CrossRef]

34. Tornøe, C.W.; Christensen, C.; Meldal, M. Peptidotriazoles on Solid Phase: [1,2,3]-Triazoles by Regiospecific Copper(I)-Catalyzed 1,3-Dipolar Cycloadditions of Terminal Alkynes to Azides. J. Org. Chem. 2002, 67, 3057-3064. [CrossRef] [PubMed]

35. Movassaghi, M.; Hunt, D.K.; Tjandra, M. Total Synthesis and Absolute Stereochemical Assignment of (+)and (-)-Galbulimima Alkaloid 13. J. Am. Chem. Soc. 2006, 128, 8126-8127. [CrossRef] [PubMed]

36. Movassaghi, M.; Tjandra, M.; Qi, J. Total Synthesis of (-)-Himandrine. J. Am. Chem. Soc. 2009, 131, 9648-9650. [CrossRef] [PubMed]

37. Wiedemann, S.H.; Ellman, J.A.; Bergman, R.G. Rhodium-Catalyzed Direct C-H Addition of 3,4-Dihydroquinazolines to Alkenes and Their Use in the Total Synthesis of Vasicoline. J. Org. Chem. 2006, 71, 1969-1976. [CrossRef] [PubMed]

38. Minatti, A.; Buchwald, S.L. Synthesis of Indolines via a Domino Cu-Catalyzed Amidation/Cyclization Reaction. Org. Lett. 2008, 10, 2721-2724. [CrossRef] [PubMed]

39. Greene, T.W.; Wuts, P.M.G. Protective Groups in Organic Synthesis, 3rd ed.; John Wiley and Sons: New York, NY, USA, 1999; pp. 219-229.

40. Kocienski, P.J. Protecting Groups, 1st ed.; Georg Thieme Verlag: Stuttgart, Germany, 1994; pp. 137-155.

(c) 2017 by the authors; licensee MDPI, Basel, Switzerland. This article is an open access article distributed under the terms and conditions of the Creative Commons Attribution (CC BY) license (http:/ / creativecommons.org/licenses/by/4.0/). 